\title{
Feminidades y memorias en contextos migratorios: algunas tensiones entre la forma narrativa y lo biográfico
}

\author{
Roberto Marín Villalobos'
}

Recepción: 8 de mayo de 2017 / Aprobación: 7 de agosto de 2017

\section{Resumen}

Este escrito reconstruye algunas narrativas a partir de relatos biográficos de mujeres hijas de madres migrantes, en el sentido Nicaragua-Costa Rica. Dichas narrativas se elaboraron dando especial énfasis a la forma en que son contadas las experiencias de nueve jóvenes entre los 18 y 26 años, por medio de entrevistas a profundidad y análisis de contenido. El principal objetivo fue visibilizar cómo la forma misma del discurso verbal puede dar cuenta de procesos de gran tensión y/o ruptura en lo biográfico. Las principales modalidades de los "accidentes del discurso" encontradas fueron: repetición, diminutivos y bloqueo de memoria. Además de representar distintas maneras de aludir a contenidos que no son dichos de manera explícita, estas modalidades de decir sin decir constituyen recursos para poner en palabras lo innombrable de sus vivencias como mujeres migrantes y/o hijas de migrantes, pero también son vías para encubrir y olvidar fallidamente tales vivencias. Lo anterior también permitió problematizar empíricamente algunas propuestas teóricas sobre la memoria y lo narrativo, discutiendo su vínculo con lo colectivo.

\section{Palabras clave}

Feminidad; memoria; biografía; narrativas; migración

\section{Abstract}

This paper reconstructs some narratives from stories around the biographical in daughters of migrant mothers, in the Nicaragua-Costa Rica direction. These narratives were developed with special emphasis on how nine young adults aged 18 to 26 narrate their experience, via in-depth interviews and content analysis. The main objective was to visualize how the very form of verbal discourse intervene on processes of great tension and / or rupture in the biographical. The main forms of 'discourse accidents' found were: repetition, diminutives and memory lock. In addition to representing different ways of referring to content that is not said explicitly, these modalities of speaking without speaking can be considered as resources to put into words the unnamable of their experiences as migrant women and/or daughters of migrants, but also ways to hide and insolvently forget such experiences. This also allowed empirically problematize theoretical proposals regarding memory and narratives, discussing their link with the collective.

1 Costarricense. Licenciado en Psicología por la Universidad de Costa Rica (UCR). Docente de la Escuela de Psicología de la UCR. Correo electrónico: edgarroberto.marin@ucr.ac.cr 


\section{Keywords}

Femininity; memory; biography; narratives; migration

\section{Resumo}

Este artigo reconstrói algumas narrativas a partir de relatos biográficos das mulheres filhas de mulheres migrantes nicaragüenses na Costa Rica. As narrativas foram elaboradas com énfasis especial em como elas são contadas, tendo como base as experiências de nove mulheres jovens entre os 18 e 26 anos, por meio de entrevistas em profundidade e análise de conteúdo. O objetivo principal foi visualizar como a própria forma do discurso verbal pode explicar processos de grande tensão e/ou ruptura no biográfico. As principais modalidades encontradas dos "accidentes do discurso" foram: repetições, abreviaturas e bloqueios da memoria. Além de representar diferentes maneiras de se referir ao conteúdo que não é dito explicitamente, essas modalidades de falar sem falar constituem recursos para colocar em palavras aquilo que é inominável das experiências das mulheres migrantes e/ou filhas de migrantes, mas também maneiras de acobertar e esquecer, falidamente, essas experiências. Isso também permitiu problematizar empíricamente algumas propostas teóricas sob a memoria e o narrativo, discutindo sua relação com o coletivo.

\section{Palavras chave}

Feminilidade; memória; biografia; narrativas; migração

Un hombre de las viñas habló, en agonía, al oído de

Marcela.

Antes de morir, le reveló su secreto: -La uva -le susurróestá hecha de vino.

Marcela Pérez-Silva me lo contó, y yo pensé: Si la uva está hecha de vino, quizá nosotros somos las palabras que cuentan lo que somos

(El libro de los abrazos. Galeano, 2009, p. 4).

\section{Introducción}

El presente artículo se enmarca en el proyecto "Relación madre-hija: un acercamiento a las cadenas transnacionales de cuidado", a cargo de la Dra. Roxana Hidalgo Xirinachs, del Instituto de Investigaciones Sociales de la Universidad de Costa Rica. Se trabajó con nueve jóvenes, hijas de mujeres migrantes nicaragüenses, mediante entrevistas a profundidad y una sesión grupal, cuya temática germinal se encuentra vinculada a la experiencia de migración de sus madres o familias y, en algunos casos, también a la propia.

Cabe destacar que el proyecto mencionado surge a partir de una investigación previa con las madres de las jóvenes participantes (Hidalgo, 2011). A excepción de una de ellas, con anterioridad, se trabajó con cada una de las madres de las participantes. Este antecedente es importante, ya que, 
tal y como se verá más adelante, permitió enlazar los relatos desde perspectivas distintas a los acontecimientos ocurridos. En especial, aquellos ligados a sus experiencias asociadas con la feminidad y la migración, en las que precisamente la relación madre-hija es trasversal. Mediante las entrevistas se realizó un doble efecto de elaboración activa: por parte de las participantes, ya que la recapitulación de sus vidas a través de lo relatado implicó no solo revisitar experiencias pasadas, sino también cierto "reacomodo" biográfico; mientras que, por parte del equipo de investigación, conllevó a la construcción de narrativas a partir de particularidades en el discurso recogido. En este sentido, la palabra, como dato, resultó ser particularmente interesante.

Desde la perspectiva metodológica, el uso de narrativas para indagar en o desde lo biográfico, es una vertiente investigativa amplia y prometedora en la que germinan aproximaciones variadas: desde el enfoque biográfico de Michel Legrand, cercano a la sociología clínica (Cornejo, Mendoza y Rojas, 2008; Cornejo 2008), hasta el enfoque de razonamiento auto-biográfico, a partir de la psicología del desarrollo y del psicoanálisis clínico (Habermas, 2011), por mencionar algunos ejemplos². En particular, la construcción de narrativas a nivel epistemológico se cuenta dentro de las "corrientes que hunden sus raíces en la crítica feminista de la ciencia, la fenomenología, el post-estructuralismo francés y su metodología deconstructivista, así como en el socio-construccionismo de origen norteamericano" (Biglia y Bonet-Martí, 2009, pp. 1-2). Se trabajó dando énfasis a las particularidades (más adelante se problematiza si se pueden considerar accidentes y/o recursos) del estilo narrativo de las participantes, re-construyendo narrativas a partir de dichas particularidades que no aluden necesariamente al contenido, sino a la forma.

El trabajo con las entrevistas fue de transcripción, en un intento de lograr la mayor fidelidad a lo dicho; sin embargo, no todo puede ser transcrito. Aun así, se busca dar a la persona lectora la mayor cantidad de señas respecto a la escena o por qué se consideró determinado fragmento textual como ejemplar. Algunas de las particularidades presentes en las narrativas de las jóvenes entrevistadas son: bloqueos o rodeos en el recuerdo, repetición de palabras o frases y el uso de diminutivos. La lista no es exhaustiva, dado el volumen de entrevistas (20 en total), el escaneo de este tipo de variantes o relieves discursivos no se puede considerar absoluto. Este, además, corresponde a aquellos relieves que el equipo de investigación consideró más significativos, por lo que se identifica un componente subjetivo, pero no del todo valorativo.

$2 \quad$ Agradezco al Dr. Javier Tapia por facilitarme estas referencias a partir de escuchar su participación en "La intervención biográfica en la formación en clínica" presentada en el coloquio Retos y perspectivas de la formación en clínica, realizado del 22 al 23 de octubre de 2015, en la Escuela de Psicología, de la Facultad de Ciencias Sociales, Universidad de Costa Rica. 
Retomando lo mencionado sobre forma y contenido, una puntualización central es: el qué es dicho se relaciona con el cómo es dicho, y viceversa. Riessman postula que:

el análisis narrativo toma como objeto de investigación las historias en sí mismas que pueden ser consideradas como una "performance" particular del narrador y que, obviamente, están influenciadas por el tiempo en el que se performatiza esta realidad y por los efectos de la memoria en la reconstrucción del pasado lejano o cercano (Reissman, citado por Biglia y Bonet-Martí, 2009, p. 8).

El término performance colabora en la indistinción del qué respecto al cómo, en el sentido de una relación en la que ambos se influyen en continua interpelación. Dadas las temáticas y tono de algunas de las entrevistas surge la interrogante: ¿cómo narrar experiencias del orden de lo innombrable? Esto acerca además a lo referido sobre la relación madre-hija, ya que lo indecible se ha asociado estrechamente con lo maternal (Hirsch, 1989), pero se ha privilegiado la posición de la madre en esta relación, dejando a la sombra de lo materno las vivencias de la "hijedad". Esta es una apreciación compartida con los estudios recientes consultados, cuya panorámica será presentada a continuación. Sin embargo, resulta relevante mostrar la principal propuesta de este artículo: la forma misma del discurso verbal puede dar cuenta de procesos de gran tensión y/o ruptura en lo biográfico, entre los que se enmarcan los significados asociados con la feminidad y la migración, con el ser hija.

\section{Antecedentes}

\section{Investigaciones actuales sobre la parentalidad en contextos migratorios desde la perspectiva de la "hijedad"}

Es importante estudiar la perspectiva de las hijas e hijos en tanto son partícipes directos de la migración de sus progenitores. Ser causa y/o experimentar las consecuencias son dos matices en una amplia gama de posibilidades. Al respecto, Carrillo, haciendo diálogo con Abdelmalek Sayad, menciona que "hablar de los hijos de los emigrantes es hablar de un caso muy particular de sujeto, porque son personas intensamente afectadas dentro del proceso migratorio sin ser emigrantes ellas mismas" (2005, p. 361). Existen claros señalamientos en cuanto a que estas voces no han sido escuchadas desde la academia en la forma en que lo ameritan, "a la fecha, la investigación que incluye la perspectiva de los hijos e hijas sobre la migración parental ha sido insuficiente" (Jampaklay y Vapattanawong, 2013, p. 377), o cuando ha sido así, se ha efectuado de manera superficial:

Los efectos subjetivos y/o emocionales para el grupo de población (NNA [niños, niñas y adolescentes] afectados(as) por el fenómeno migratorio) son, en la mayoría de los casos, analizados superficialmente, identificando posibles repercusiones negativas en el rendimiento escolar y en el área psicosocial como si éstas (entre muchas otras) no formaran parte del desarrollo general de NNA bajo el enfoque 
de derechos y son además atendidas desde enfoques claramente adultocéntricos (UNICEF, 2012, p. 104).

Es decir, de manera tradicional, solo se estudia sobre los progenitores y, cuando se hace sobre sus hijas e hijos, se hace con metodologías o concepciones no pensadas para estos o que carecen de la flexibilidad suficiente. En esta línea, López acota que en el análisis de la migración, como fenómeno social, se ha privilegiado el papel económico de los hombres y, en cada vez más estudios, el de las mujeres; pero el de los niños, como actores sociales que también están inmersos en la migración, no ha sido abordado sistemáticamente (2007, p. 545).

En el caso de esta investigación hay, quizá, una doble marginalidad: son mujeres y son jóvenes. Algunas repercusiones encontradas en estudios académicos sobre la vida de estos hijos e hijas, construidas con sus propias palabras se pueden, grosso modo, puntualizar así:

\section{Desequilibrio en las cargas de género en los procesos de migración}

Se espera que las madres sean las principales cuidadoras, siendo crucial su lugar en el desarrollo de los y las hijas, y por ende irremplazable. Los resultados de Jampaklay y Vapattanawong (2013) apuntan a que, a hijas e hijos, les parece que la familia funciona mejor cuando los padres trabajan y las madres cuidan. Así, respecto a la responsabilidad de cuido, para efectos de la presente investigación, es importante resaltar que, según lo hallado por Zapata (2009):

las hijas son las principales encargadas de realizar las tareas domésticas (preparar las comidas, limpiar la casa, lavar la ropa, planchar), de suerte que se sienten responsables del bienestar de los demás miembros de la familia, al sustituir el lugar de la madre migrante (p. 1761).

\section{En cambio:}

cuando los hermanos o hermanas menores quedan bajo el cuidado de hijos hombres-, se contrata una empleada que se le remunera por las tareas domésticas que realiza ... si no se contrata a una empleada doméstica entonces se cuenta con la red familiar femenina -tías, abuelas, hermanas, primas - que se encargan de tal función (p. 1762).

\section{Lo anterior coincide con Pavez-Soto (2010):}

Respecto a las relaciones de género y a la distribución del trabajo del hogar, en nuestras entrevistas observamos que la labor doméstica sigue siendo vista como una responsabilidad eminentemente de las mujeres y las niñas, aunque los niños y los adolescentes también señalan que cooperan en diversas tareas caseras" (p. 453). 
En esta misma línea, Micolta (2011a) propone:

El trabajo empírico viene mostrando que el cuidado de los hijos de las y de los migrantes está principalmente en manos de otras mujeres de la familia, quienes asumen las tareas de cuidado de niños y niñas, para que las madres migrantes asuman el cuidado de otros en los países a donde llegan (p. 4).

Como puede apreciarse, existe una clarísima tendencia en diferentes contextos latinoamericanos a que se naturalice la función de cuido como propia de las mujeres, situación que se repite en Costa Rica (Carcedo, Chaves Groh y Lexartza 2011 y 2012).

\section{Toma de decisiones sobre asuntos familiares o caseros a larga distancia}

Según Puyana y Rojas (2011), pese a que en ocasiones la migración de progenitores es percibida como una especie de sacrificio necesario -con tonos de heroísmo- persiste una ambigüedad emocional, que hace que situaciones de despedida abrupta también se vivan como abandono. Suelo sobre el cual se generan tensiones cuando los progenitores toman decisiones acerca de la dinámica o situación familiar a la distancia o incluso cuestiones específicas en la cotidianidad de sus hijas e hijos, por ejemplo, cuando dan o niegan permisos para asistir a actividades escolares y/o sociales. En este escenario, la injerencia de los progenitores se ve afectada, ya que según Micolta "para conservarla [la autoridad], deben responder al menos a dos expectativas sociales frente a la parentalidad: mantener la vinculación emocional y la proveeduría económica de los hijos a través de las remesas económicas" (2011b, p. 22), es decir, mantener un vínculo afectivo y velar porque las necesidades sean satisfechas, muchas veces provistas a través del dinero, lo cual trae a su vez algunas implicaciones, como se verá a continuación.

\section{Beneficios y maleficios de las remesas}

El tema del dinero es áspero y los escenarios y posibilidades presentadas por las y los autores consultados son diversos. Se encuentra el panorama en que según las palabras de hijas e hijos:

se solicita dinero o materiales escolares cuando se necesitan realmente y no para manipular o conseguir objetos de consumo ... son las madres y los padres quienes utilizan el envío de regalos y las "propinas" como una forma de estar presentes simbólicamente (Pavez-Soto, 2010, p. 447).

No obstante, también se presenta una faceta menos cálida:

La dependencia económica hace que las actividades de los hijos y las hijas giren en torno a los envíos de dinero y se limiten, en consecuencia, las oportunidades personales, laborales y académicas a largo plazo -en algunos casos-, puesto que esperan que sean otras las personas que continúen aportando económicamente ... construyen relaciones familiares que se vuelven utilitaristas, pues el 
dinero se convierte en un fin en sí mismo y las personas -el padre, la madre o familiares-, los medios para obtenerlo. El dinero es además el justificante de la ausencia del padre o la madre y la razón por la cual no es conveniente que se realice un retorno (Zapata, 2009, p. 1759).

Como puede observarse con claridad, el dinero puede ser utilizado como moneda de afectos, ya sea por parte de figuras parentales o de las hijas e hijos mismos. Se vislumbra que el dinero puede ser también razón para el no retorno, independientemente del interés que tengan quienes están involucrados en la migración.

\section{Dificultades y recursos para la comunicación}

En un estudio de caso en el que la hija convive con su madre en la casa de sus empleadores, su investigadora comenta que el testimonio de Olivia vuelve una y otra vez sobre sus dificultades para disponer de un tiempo privado con su madre, por fuera del tiempo de trabajo, y construir una relación que escape a la influencia y la presencia de sus empleadores (Tizziani, 2013, p. 249).

Cabe preguntarse, en relación con el caso referido, ¿cuánto más ante un distanciamiento geográfico de cientos de kilómetros? Para Puyana y Rojas (2011) el uso de tecnologías ha revolucionado las posibilidades de contacto, ya que brinda cierta inmediatez, reducción de costos y posibilidad de intercambio de comunicación más allá de la voz, mediante fotos, videos, etcétera. Al respecto, Zapata agrega que los intercambios afectivos se dan también por vías como los regalos, los cuales

comunican, expresan y simbolizan el afecto, y por lo tanto la presencia del padre o de la madre, que aunque estén separados en el tiempo y en el espacio de sus hijos y de sus hijas, permanece emocionalmente y mantiene vivo su recuerdo: 'Yo veo ese joyero y me acuerdo inmediatamente de ella' (hija de 13 años); 'es como el recuerdo de mi mamá' (hija de 14 años) (2009, p. 1756).

Se identifican formas de comunicar y de recordar que van más allá de las palabras, lo cual se relaciona de lleno con la temática del presente artículo.

\section{Actividades a las que se dedican luego de la partida de alguno o ambos progenitores}

Como ya ha sido mencionado, algunas de las participantes de la investigación que fueron entrevistadas, no migraron junto con sus madres y/u otros miembros de la familia, mientras que otras sí. En cuanto al primer caso, Berrecil, González y Ampudia, proponen:

los que se quedan viven en condiciones precarias, su familia es dividida y algunos de ellos se incorporan a actividades remuneradas con tal de apoyar a su familia, se dedican a las labores del hogar o se quedan al cuidado de los hermanos menores (s. f., p. 3). 
Este escenario se presentó en la mayoría de las participantes que se quedaron en sus casas, a lo que se suma la sobrecarga de responsabilidades adjudicadas a ellas por cuestión de género. Algunas de las participantes no viajaron junto a sus madres, pero sí lo hicieron de forma posterior. Las razones varían, pero se alinean con lo planteado por Pavez-Soto: "Las niñas y los niños tienen variadas motivaciones para viajar, desde la esperanza de volver a estar junto a sus progenitores, hasta las expectativas de estudiar y conocer un nuevo país muchas veces idealizado" (2010, p. 448).

En algunas de las entrevistas se menciona que Costa Rica les era presentada como un destino ideal lleno de cualidades positivas. En este sentido, cabe preguntarse si en las comunidades de origen de estas participantes existe cierta cultura y socialización en pro de la migración, ya que ciertos grupos, cuyos miembros desde generaciones anteriores han migrado, fomentan y reproducen de manera sutil, pero muy directa, anhelos de migración desde edades tempranas:

Los niños migrantes y los hijos de migrantes viven "la dureza del mundo"... a través de la separación, la ausencia, el desarraigo, la angustia y los recuerdos, todo ligado a la migración. Para minimizar el sufrimiento, la sociedad los "prepara" a través de la socialización de las virtudes, los riesgos y las oportunidades que significa la migración. De esta manera se llega al punto de no cuestionarse la idea de ir a vivir, estudiar y trabajar en el norte: la vida es así y no de otra manera [cursivas añadidas]. En eso reside la tragedia (López, 2007, pp. 567-568).

\section{Aspectos positivos de la migración de progenitores}

Pese a que no hay una vulnerabilidad per se ante la migración de alguno de los progenitores, muchas hijas e hijos se encuentran frente a nuevos retos, los cuales, en ciertos casos, fomentan "las capacidades de las personas, recursos internos, que concedan alternativas de acción y uso de estrategias; y aptitudes, que les permiten afrontarlas y mejorar sus condiciones de vida, así como encarar los procesos y superarlos" (UNICEF, 2012, p. 135). Cabe agregar que en esta publicación destaca el hecho de que este escenario se da, especialmente, cuando hijos e hijas perciben a este progenitor como una presencia nociva en el ámbito familiar, por lo que un corte de relaciones se convierte en un alivio. Lo anterior es cuestionable, ya que las relaciones con los progenitores son complejas, teñidas de múltiples matices emocionales, por lo que no son tan negativamente puras.

A diferencia de estos cortes repentinos o tajantes en el vínculo, cuando se sostiene cierta continuidad en las relaciones hijos-progenitores, hay una mejor percepción de los progenitores y del migrar en sí, aún más cuando

la decisión de migrar es tomada en conjunto con los hijos e hijas, a quienes se les da un papel activo en dicha decisión. Los padres y madres realizan rituales de despedida, que aunque descritos como muy tristes, permiten tramitar el dolor de un modo productivo para ambas partes (Puyana y Rojas, 2011, p. 106). 
En esta misma línea, Pavez-Soto afirma que: "Cuando las personas adultas facilitan un proceso participativo dando la posibilidad de opinar y decidir, las hijas y los hijos se sienten más responsables y también protagonistas de este plan" (2010, p. 448). Cabe destacar que este no fue el caso en casi ninguna de las historias contadas por las participantes.

Por último, posiciono algunas apreciaciones que, en general, dejó el escrutinio de investigaciones sobre migración desde la perspectiva de la hijedad. La migración de los progenitores vivida por sus hijas e hijos no es inherente ni mucho menos positiva o negativa.

[C] Jestionar tanto [1] las generalizaciones vagas sobre los efectos en las relaciones entre padres, madres, hijos e hijas cuando se presenta la migración internacional de los progenitores, como [2] las de quienes sostienen que cuando hijos e hijas permanecen en el país "son huérfanos", y se les debe señalar como población en riesgo, con dificultades para su desarrollo emocional. Ninguna de las dos posturas señaladas [1 y 2] reconoce las diferencias y la heterogeneidad de la forma como se produce el proceso migratorio (Puyana y Rojas, 2011, p. 108).

Bajo el nombre "familias transnacionales" se engloba a los miembros de la familia y se habla de un abordaje integral, sin embargo, esto no implica tomar la palabra de los hijos e hijas, escucharles directamente. Por ejemplo, se destaca que "la paternidad y la maternidad transnacional configuran nuevas formas de ser 'padre' y 'madre'” (Zapata, 2009, p. 1763), pero no se menciona sobre nuevas formas de ser "hija" o "hijo", más allá de hablar de una "adultez precoz" o "parentificación" al asumir responsabilidades de sus progenitores.

El retorno también es mencionado como un aspecto a tomar en cuenta para futuras investigaciones (Zapata, 2009; Herrera, 2013). El retorno ocurrido en varias de las jóvenes entrevistadas que emigraron con sus madres implicó que, en ciertas ocasiones, el ser enviada de regreso a Nicaragua constituyera una forma de castigo y/o una forma de vigilancia por alguna figura de autoridad familiar, usualmente abuelas o abuelos, con la finalidad de que se "comporten bien".

\section{Investigaciones que incluyen la forma narrativa y no solo contenido}

Si las investigaciones encontradas que toman en cuenta las voces de hijos e hijas son, cuanto menos, proporcionalmente pocas, aquellas que se preguntan por lo que se expresa a través y más allá de lo dicho se perciben como nulas. No obstante, sí se hallaron algunas inquietudes, por ejemplo Herrera (2013) menciona en relación con el cuidado, que:

En las representaciones de nuestras entrevistadas, cuidadoras en su mayoría, no se percibe una valoración del mismo, y los esfuerzos físicos y mentales que representa el quedarse a cargo del cuidado de menores o adultos mayores es verbalizado únicamente cuando se pregunta explícitamente por él [cursivas añadidas] (p. 146). 
Con esto, se hace visible que hay temas que no surgen en el discurso de las entrevistadas y que aparecen verbalizados solo cuando se indaga directamente; sin embargo, existe en la manera de verbalizar -sin aludir explícitamente a nivel de contenido- una vía para poner en palabras lo inenarrable. Por tanto, las distintas vicisitudes de apalabrar lo vivido serán abordadas a continuación desde una perspectiva más bien teórica, para luego pasar a la construcción de narrativas a partir de las entrevistas a las jóvenes participantes, en las que serán presentadas algunas modalidades en que la forma también dice algo.

\section{Consideraciones teóricas sobre la memoria y lo narrado}

En esta sección se expondrá una discusión y delimitación conceptual: la tensión entre memoria y narración, así como los "accidentes" que surgen del vínculo entre ambas. Como punto de entrada, es relevante señalar que se considerará una aproximación crítica del constructo de memoria más "clásico", es decir, no entendiéndola como una facultad exclusivamente individualintrapsíquica o un fenómeno enteramente biológico ni como una recuperación de contenidos preservados de manera intacta por el sujeto. Más bien, se va a parte de que esta es "un fenómeno colectivo, o social, no solo porque se refiera a un contenido que alcanza a grupos grandes de personas, sino porque, necesariamente, se articula en las relaciones sociales y se compone mediante procesos y prácticas sociales que las definen" (Dobles, 2009, p. 41).

En el caso de las jóvenes participantes en la investigación, cabe destacar que las entrevistas no giraron exclusivamente en torno a la temática de la relación madre-hija, sino también sobre otras relaciones sociales, entre ellas: familiares, de amistad, de pareja, laborales, educativas, entre otras. Siguiendo la propuesta de Augé, Dobles (2009) se retoma la siguiente distinción entre recuerdo y memoria considerada valiosa para el presente trabajo:

el recuerdo tendría que ver con las huellas mnémicas, individuales -que, sin embargo, ya hemos visto no se producen en solitario- y así, los recuerdos y los olvidos serían procesos más individuales; la memoria, sin embargo, compuesta por estos dos ingredientes, nace cuando los recuerdos, que implican también a los olvidos, son puestos en palabras, entrando así en lo social e inter-subjetivo [cursivas añadidas] (p. 130).

Tenemos entonces que la visión más estable, lineal e individual -anteriormente llamada "clásica"- de la memoria, correspondería más bien al recordar (en la que además se considera el olvido como un déficit mnémico), mientras que esta otra perspectiva brinda mayor amplitud y flexibilidad a este constructo. A lo anterior se adiciona que lo social de la memoria no está dado únicamente por elaborarse a partir de relaciones sociales, sino por ese ser puesto en palabras. 
En relación con los relatos de las participantes, vendría a ser una memoria construida socialmente, echando mano de recursos culturales y expuesta de manera "artificialmente" cotidiana -como lo es la modalidad de entrevista a profundidad. Se conforma así una narrativa biográfica enunciada de forma personal sobre acontecimientos de interacción social, haciendo a su vez uso de una herramienta cultural como lo es el lenguaje. Conviene señalar que, tanto en la memoria como en el lenguaje, se diluye la frontera entre lo individual y lo colectivo ${ }^{3}$.

La conexión entre memoria y narrativa es también robusta, ya que la narración siempre es una forma particular de tejer y reconstruir el recuerdo. Un recuerdo que nunca será literal, ni completo, ya que siempre surgirá de la rememoración del pasado a partir de las posibilidades que el presente nos ofrezca (Benjamin, 1940). No existe un acceso pleno a la memoria, e incluso elementos que sí logran ser recordados, no son, de forma necesaria, traducibles a lo enunciable. La posibilidad de que haya aspectos que no son recordados conscientemente -por ejemplo, la emigración de la madre- pero que aun así surgen en el discurso como particularidades en el modo de hablar es, de manera precisa, la dimensión de lo narrativo a recalcar en la reconstrucción de narrativas que se presentan en el siguiente subapartado. En pocas palabras, la memoria está presente no solo en qué, sino también en cómo se habla; entonces, cómo se habla constituye una forma de recordar... y de olvidar. Mucho de lo planteado aparece condensado por Ricoeur en la siguiente cita:

La narración emerge a través de relatos elaborados, no a partir de una reproducción exacta, escrupulosa y lineal de la sucesión de acontecimientos, sino que se produce secuencialmente, estableciendo relaciones, aportando detalles, introduciendo conocimientos socialmente compartidos, pudiéndose desplazar a través del pasado, del presente y el futuro, aprovechando la virtualidad que la narración tiene de poder reconfigurar el tiempo (Ricoeur, citado por Dobles, 2009, p. 134).

Como puede apreciarse, en lo narrativo se juega lo temporal como artilugio de virtualidad; de manera curiosa, una virtualidad en acto, ya que "como prácticas discursivas, las narraciones no sólo son palabras sino acciones que construyen, actualizan y mantienen la realidad" (Cabruja et al. citados por Biglia y Bonet-Martí, 2009, p. 8). Esta afirmación -más que brindar cierta resolución a lo poroso y frágil de los límites entre memoria y narración, pensamiento y palabra, idea y acto- nos introduce en la discusión por la realidad, ¿ha de ser tomada la narración biográfica como realidad histórica de quien la enuncia?

Es importante no idealizar. Se cae en una tremenda ingenuidad al pensar que lo biográfico (siendo también una narrativa) es un relato enteramente

3 Con especial énfasis se abordará la problematización de las fronteras con respecto al tema migratorio; no obstante, también otros límites serán abordados: forma-contenido, madre-hija, olvido-recuerdo, silencio-palabra. 
coherente y lineal. Ha de figurársela como una ficción agujereada y móvil. Sobre esto nos alerta Bourdieu, al aludir a la "ilusión biográfica": "se querrá 'pulir' la elaboración narrativa de la memoria, redondearle los extremos demasiado agudos, cubrir las fracturas con coherencias" (Bourdieu, citado por Dobles, 2009, p. 135). El objetivo del presente artículo es precisamente lo contrario: subrayar diversas texturas -ya sea lo puntiagudo, lo esponjoso, lo cristalizado, entre otras- de las narrativas recopiladas para aproximarse a las experiencias de vida de jóvenes cuyas madres han migrado, experiencias que, con frecuencia, cayeron en el registro de lo indecible. Lo anterior sin una finalidad de interpretación última, de dar sentido o de restitución histórica, ni mucho menos de considerar estas texturas como deficiencias psicológicas o anormalidades lingüísticas.

Si bien la narración biográfica no es sinónimo de realidad empírica, tampoco queda del lado de la fantasía o abstracción pura, ya que esta ficción toma materiales de una realidad de vida. De manera precisa, "si hubiera que adscribir la autoficción a alguna estética precisa sería a la hiperrealista en la medida que este tipo de relatos proceden con la misma estética del hiperrealismo plástico: exalta una apariencia extrema de lo real hasta prácticamente desrealizarlo" (Alberca, 2007, p. 50). Claramente, el autor señala lo anterior a propósito de la literatura de autoficción, sin embargo, cabe tomarlo en cuenta a la hora de pensar sobre otras modalidades narrativas no necesariamente literarias. En suma, no se busca saber o interpretar La Realidad de quienes evocaron las distintas particularidades a través de lo narrativo, sino hacer ver que el modo mismo en que narran sus experiencias forma parte de esa (su) realidad: de ser mujer, hija, migrante y/o hija de una mujer migrante.

Entramos, pues, al tercer componente conceptual: los "accidentes" ocurridos en la conjugación de la memoria y lo narrativo. El carácter "accidental" no deriva de lo catastrófico, sino del orden de un acontecimiento inusitado. Esta es una discusión que se plantea también desde la lingüística:

Es embarazoso, desde un principio, para una gramática, ser concebida para iluminar hablantes que casi nunca comenten errores..., y no tener nada que decir sobre los "errores" que los hablantes hacen todo el tiempo, "errores" ciertamente que son el error adecuado, por así decirlo, que hay que cometer (Hymes, citado por Muro, 2011, p. 29).

Destaco el entrecomillado de la palabra errores, ya que ejemplifica la condición paradojal de lo accidental del lenguaje; es decir, su oportuna impertinencia. Esto conlleva a considerar estos accidentes como excepciones, entendiendo por excepción como un "error" aceptable y necesario: "la excepción otorga sentido y articula toda la estructura" (Dobles, 2009, p. 127). En el campo de la memoria y lo narrativo, se trataría de una estructura de lenguaje. Ya sea desde la lingüística (Émile Benveniste en su lectura de Saussure) o desde el psicoanálisis (Lacan en su lectura de Freud), hay una gran cercanía respecto a la cuestión psíquica y al lenguaje. Una de las más des- 
tacadas obras de Freud, en la que trabaja de lleno y muy explícitamente esta relación, es Psicopatología de la vida cotidiana, de 1901. Sin entrar en más detalle que el mismo título, puntualizo, en vista de lo mencionado sobre el "error", que lo extra-ordinario (frecuente e inusual a la vez) equivaldría a lo cotidiano. Sin embargo, de lo psicopatológico (en su sentido amplio y popular, no en el sentido en que el mismo Freud problematiza lo normal-enfermizo) sí se toma mayor distancia, puesto que no se intenta patologizar la desmemoria o lo accidental narrativo, ni mucho menos que las diversas accidentalidades representen una feminidad o una experiencia directa o indirecta de migración o de relación madre-hija, irremediablemente accidentadas. Tampoco es el discernimiento de formaciones inconscientes en las participantes a través de sus entrevistas la meta buscada, sino reseñar que hay efectos de lo inconsciente en el uso del lenguaje que no carecen de relevancia en las investigaciones que tomen como unidades de análisis las narrativas.

\section{Resultados. Re-construcción (dis)narrativa: evocaciones ¿equívocas?}

Como puede apreciarse, el subtítulo de esta sección busca retomar los siguientes aspectos relativos a la relación entre memoria y narración: 1) Se trata de una re-construcción, ya que se eligieron fragmentos de las transcripciones hechas a partir de entrevistas a profundidad, por lo que la manera como ahora es presentada es elaboración de quien investiga. 2) El prefijo antagónico entre paréntesis fue colocado ya que esta re-construcción no da como resultado un texto o conjunto de textos en un orden narrativo, en su sentido tradicional, sino que algunos de los rasgos antes mencionados sobre la narración y la memoria (no lineal, inexacta, etcétera) aparecen exaltados. 3) No toda equivocación es-del todo ni siempre-fallida.

En el abordaje de lo narrativo se vuelve fundamental, entonces, poder explorar las rupturas, discrepancias, incoherencias, contradicciones y ausencias en el discurso (Hidalgo, 2011). Esta exploración se realiza abriendo interrogantes, apuntando a conjeturas más que declarando certidumbres. A continuación se exponen algunas modalidades de los "accidentes del discurso" encontradas en las entrevistas realizadas, a saber: repetición, diminutivos y bloqueo de memoria ${ }^{4}$.

\section{Repetición}

Los fragmentos seleccionados corresponden a una misma participante (E.) en distintas entrevistas. Primer fragmento:

4 Simbología. EE significa: Entrevistador o Entrevistadora. La letra mayúscula sola representa la inicial/ pseudónimo de la participante. La cursiva se emplea para señalar porqué se considera repetición, disminución, bloqueo. 
E.: Ahí después cuando quedamos con mi papá era solo palo, era solo palo, era solo palo.

EE: ¡Qué duro!

E.: Sí, una vez estaba dormida yo, y cuando sentí el fajazo que me caí de la cama.

Yo ya casi era... no era mujer, pero ya tenía 15, 16.

EE: ¿Que pasó, estaba borracho?

E.: No, ya no le seguían mandando la plata a él, sino que me la mandaba a mí. Y eso fue como que le echaron chile picante a él.

La madre de E. emigró de Nicaragua a Costa Rica sin otros miembros de su familia. Inicialmente, enviaba dinero de manera directa a su esposo -padre de E.-; no obstante, dejó de hacerlo debido a que este lo despilfarraba o gastaba en otras parejas, por lo que la nueva receptora fue E. Esto implicó una serie de tensiones traducidas en severas y repetidas agresiones (palo, palo, palo), una de ellas se muestra en el primer fragmento. Cabe destacar que, aún en el momento de la entrevista, E. no considera que en ese tiempo fuera ya mujer, aun así esta "proto-mujer"5 se ve encargada de administrar el dinero enviado por su madre de manera adecuada para el bienestar de su familia, situación que la obligó, al mismo tiempo, a enfrentarse con situaciones de violencia extremas.

Segundo fragmento:

E.: Y él [padre] era de las personas que no, solo gritar, solo gritar, solo gritar. Ya cuando mi tía [hermana de su madre] se fue era peor, ya no teníamos un escudo protector, entonces tuvimos que defendernos solos.

Ahora es mediante su voz que agrede, sin embargo, aparece la figura de su tía quien colabora arduamente en las tareas y responsabilidades familiares. Esta tía no se fue por decisión propia, sino que fue echada por la madre de E. Dicha decisión crucial fue tomada a la distancia y sin consulta a ningún otro miembro del grupo familiar, por lo que E. y sus hermanos quedaron en condiciones de vulnerabilidad. En la entrevista, E. detalla lo trágico de esta separación y lo mucho que le resiente a su madre esta determinación, la cual a la cual se alude en el tercer fragmento:

E.: Entonces cuando a veces venía mi mamá, no me importaba si venía o no venía, me daba igual, me daba lo mismo de los... de los 15, 16, 17, 18, esos cuatro años fueron frustrantes, yo no la quería ver... pasaban muchos problemas cuando ella mandaba... o sea cuando ella mandaba la plata era por una parte la felicidad, pero por otro era más amargura que felicidad.

EE: ¿Por tu papá?

$5 \quad$ Este término es utilizado haciendo caso a lo expresado por E., ante lo cual de igual manera es relevante preguntarse: ¿qué es ser mujer para E.?, ¿por qué era "casi” una mujer? ¿Es solo una cuestión de edad? 
E.: Sí, porque a quien se los mandara, siempre lo quería para él, siempre lo quería para él, lo quería para él, y yo decía a mi papá que si ella [su madre] no se hubiera peleado con mi tía no hubieran pasado tantas cosas.

Por un lado, un padre agresor; por otro, una madre que, por motivos cuestionables para E., la deja sin la tía que funcionaba como "escudo protector" frente a la arbitrariedad y violencia paternas. El dinero aparece prácticamente como un mal necesario, en el sentido de que más allá de "la felicidad" hace que pasen cosas dolorosas. Es relevante cuestionar acá los agentes causales a los que apunta E. de que "hubieran pasado tantas cosas", ya que parece responsabilizar más a su madre y al dinero por las acciones de su padre ique a su propio padre! Quizá haya un resentimiento, que no se puede nombrar, por el hecho de que su madre se haya ido, que no se haya ido otro, e incluso parece haber una referencia, frente a tanta violencia, a que el dinero no vale la pena, a que el dinero también puede ser un bien innecesario. La repetición aparece en otro ámbito: el estudio de la tía. Cuarto fragmento:

E.: Sí, entonces, es que siempre estaba ahí [su tía], lo único es que ya cuando ella toma el rol de madre de nosotros, ella deja de salir, ya solo estudiaba, estudiaba, estudiaba.

Ahora la repetición aparece a propósito de una especie de encierro autoimpuesto, en tanto la tía "deja de salir" en el momento en que toma el rol materno. En esta ocasión, se hace explícito el lugar de madre que su tía ocupó, sustitución que es insuficiente y que marca una nueva ausencia, provocada por la madre. E. plantea como exigua la presencia de su tía, ya que algunas cargas tradicionalmente adjudicadas al rol materno eran también desempeñadas por ella misma, en tanto se ocupaba, por ejemplo, de alistar las cosas de sus hermanos para que pudieran asistir a sus respectivos centros educativos. Esto, entre otras cosas, ocasionaba situaciones como las del quinto fragmento, pues al llegar tarde a la escuela:

E.: No nos dejaban entrar, y teníamos que esperar hasta que le roncara para que nos dejara entrar. Y ya cuando nos dejaba entrar, teníamos que hacer mil líneas "no vuelvo a venir tarde", "no vuelvo a venir tarde", "no vuelvo a venir tarde". Y entonces después algunos se burlaban.

Todavía, en el ámbito del estudio, ahora la repetición aparece como castigo, a pesar de no ser directamente responsables de llegar tarde. Vinculado a un castigo sin culpa, la repetición también aparece en su relación de pareja, de nuevo en situaciones de conflicto y violencia. Sexto fragmento:

E.: Yo todavía no vivía aquí, estaba recién casada viviendo allá en su casa, en la casa de los padres, pues de él. Y llegué [andaba en una cita médica y luego fui a la casa de una amiga], y él estaba ¡Uff! Pero que echaba, así como un dragón, fuego por aquí, fuego por aquí, fuego por todos lados. Discutimos en el cuarto, lo cual me dio un susto, cuando yo me estoy cambiando la blusa, porque ya andaba yo súper acalorada. Entonces viene él, cuando me dio un susto, lo veo yo con la faja, y entonces... y viene él, me dio como cuatro fajazos. 
En su padre era palo, palo, palo, ahora con su pareja es fuego, fuego, fuego; se hace tangible una repetición más: los fajazos, tanto su padre como esta pareja arremeten contra E. utilizando la faja como instrumento de agresión. Ahora la repetición es también biográfica. Además de presenciarse a la hora de relatar un conflicto, se da como forma de terminar con uno, o más bien, de terminar su relación de pareja que describe como conflictiva. Séptimo fragmento:

E.: Hace seis meses. Bueno, nosotros nos separamos definitivo, definitivo hace ya un año, vamos a cumplir el doce de noviembre, que a mí me operan ese mismo día. Bueno, yo vengo a la casa, pero él viene y estábamos en planes de irnos de aquí de la casa para buscar independencia, pero yo le decía a él que eso era como algo ilógico, porque ya la otra vieja estaba embarazada.

EE: ¿Ya vos sabías?

E.: Sí, porque fue... "es algo ilógico" le decía yo, "seguir creyendo de ilusa que vos me vas a sacar de aquí" le digo yo, "eso es mentira, así que mejor te vas".

EE: ¿Estabas recién operada?

E.: Estaba recién operada cuando yo le digo, le dije "ya no", "ya no", "ya no".

Este "ilusa" puede tomarse como ilusión de que su pareja, un hombre agresor e infiel (suena como un eco de su padre), la va a sacar de la situación actual. Con un triple "ya no" dejó de creer y tomó la decisión de separarse. Aunque "cierra" esta relación evocando una repetición, hay un retorno. Ella misma ¿repite? respecto a su hijo. Octavo fragmento:

E.: Entonces ya, si le quito la compu comienza a llorar y llorar de nada, y eso también lo castigan aquí [casa de los abuelos paternos del niño], que él comience a llorar de nada. Entonces dicen "ay que chavalo más maricón, que llorón, que grita y que llora". Entonces... y... y... y que Ilore de nada, y que me estén diciendo todavía que es un maricón, y me enojo. Entonces vengo y le digo "ahora si va a llorar de verdad", bam, bam, bam, "ya te dí, ahora llorá de verdad" (risas de E.).

Varios elementos reaparecen: castigo y agresión. Se colocó anteriormente la palabra "repite" entre signos de interrogación ya que nuevamente la repetición aparece en ocasión de regaño y/o de agresión parento-filial: padre-hija en primera instancia, madre-hijo posteriormente, ante lo cual cabe preguntarse: ¿reitera el uso de la repetición al hablar sobre agresión, o también repite en acto y forma la agresión? Por último, la risa surge como un aspecto nuevo y siniestro a la vez, puesto que se coloca como algo inédito en sus narraciones al tiempo que contrasta con el llanto de su hijo. Es como si sellara con la risa el haber transformado un llorar de nada a un llorar de verdad.

\section{Diminutivos}

En general aparecen en su uso gramatical usual, bajo las terminaciones "-illo", "-illa", pero no "-ito" o "-ita". Se trata nuevamente de una sola participante (J.). Noveno fragmento: 
J.: Entonces una vez tuve un problema con mi mamá, entonces cuando yo me tenía enojada con mi mamá entonces no me importaba si se daba cuenta de algo, entonces una vez... una vez... creo que mi mamá encontró el papelito y entonces ella me preguntó: “¿A usted le gustan las mujeres?” Me lo preguntó así y entonces agarré valor, estaba enojada con ella y entonces le dije: "Sí, sí me gustan”, creo que se puso a llorar, me preguntó “¿qué?... ¿por qué?” que si alguna vez un hombre me abusó, un hombre, una mujer, cosillas así... este entonces ya le dije que abusar, abusar no, pero que sí hubo alguillo, así ya.

El siguiente fragmento mantiene un tono muy similar, por el momento vale subrayar la idea o prejuicio de que una orientación sexual que no sea heterosexual vendría a estar explicada por algún encuentro sexual no consentido. En este caso -sin apuntar a un estatuto causal- sí ocurrió algo o "alguillo", lo cual nos lleva al décimo fragmento:

J.: Digamos yo he tenido así como que traumillas ya, digamos cuando estaba chiquitilla, por ejemplo. Digamos, vivíamos en una casa, había una muchacha que tiene ahorita unos 27, por ahí anda tal vez. No abusar, tal vez ella, diay no sé, como que yo me acuerdo que estaba en el cuarto y me llamó y se me subió encima. Yo no sabía nada de eso, pero no le voy a mentir, sí me gustó. Después el hermano de ella que una vez me agarró y hacía que me penetraba, eso sí que no me gustó, porque hubo como un fuerceo de parte de él. En cambio el de la muchacha no, o sea yo me dejé, en otra palabra, pero él fue como un fuerceo ya, no me gustó. Cosillas así, que tal vez me han salido hombres así, enseñándole a uno sus partes íntimas, desde chiquitilla entonces son cosas que sí me han afectado. A veces no sé si serán ideas mías, a veces siento que tal vez sí me pasó algo [pausa breve]. Como que uno lo siente ya... pero no tiene clara la imagen, varillas así ya. Este y... nada más, cosillas así me han pasado, así una experiencia así de violación-violación, gracias a Dios no, verdad, por dicha. Pero sí he pasado así como malos momentillos con hombres, más que todo con hombres, una mujer no. A veces creo que soy un poco confiada en el sentido que tal vez conozco un maecillo y me tira el cuento y yo le dijo: "Vea si usted quiere puede ser mi compa, porque nada más porque yo soy así". Ah, entonces dicen: "diay sí está bien", y entonces uno dice, bueno si lo tomó es porque no le molesta, usted sabe que a veces el hombre como es, después andan viendo como lo llevan a uno entre las patas y: "hagamos un trío". Una vez tuve así una mala experiencia con un maecillo y una muchacha ahí y uno dice: "iqué varas como hay mujeres que se prestan!" Ya entonces he tenido así mis malas experiencillas, cosillas así que a veces no confío mucho en el hombre por eso. No sé qué más decirle, no sé.

Recapitulando, J. habla de "traumillas" y cuenta dos experiencias corporales, con una mujer y con un hombre; no lo considera "violación-violación" (¿una violación no-violación entonces?), como tampoco otras "cosillas" o "varillas" como hombres exhibicionistas, "malos momentillos" que le han pasado desde "chiquitilla" y que, pese a no considerarlos violación-violación, afirma que sí le han afectado. A esto se suman otras "experiencillas" con "maecillos" que le hacen desconfiar de ellos, parece unificar bajo la enunciación "el hombre" a todos los hombres que conoce, al decir por ejemplo: "a veces no 
confío mucho en el hombre". Si bien es cierto hay un señalamiento de que estas vivencias han influido en su orientación sexual, dicha orientación no está disgregada de su construcción identitaria femenina.

Consonantemente, en ciertos usos de nuestra lengua, lo diminutivo viene acompañado de un cariz despreciativo, quizá disminuye y desprecia a la vez a los hombres y lo que estos le han hecho. Asimismo, lo diminutivo puede estar asociado con disminución o reducción de la importancia de algo. El abuso sexual, la violación o algo cercano a ella, el maltrato y la violencia en la relación madre-hija o mujer-hombre, vienen a ser nombrados como "cosillas", "varillas", "traumillas", e incluso "malos momentillos" que ella ha vivido desde "chiquitilla". Como si de alguna forma esto le permitiera tolerar mejor lo narrado, el recuerdo se hace tolerable si lo reduzco o disminuyo en su importancia, sino podría volverse inmanejable.

Si bien es plausible que estos malos momentos son propiciados por un hombre -al tiempo que afirma no haberlos pasado con alguna mujer-, hay también un reclamo hacia "las mujeres que se prestan" para determinados actos, sin embargo, estas no son llamadas maecillas. Además del diminutivo en su terminación, aparece de manera adverbial, tal y como se aprecia en el undécimo fragmento:

J.: Bueno, antes, a veces me llevaba muy mal con ella [su madre], peleábamos mucho. Mi mamá era un poco como histérica. Nosotros éramos un poco desobedientes también, pero a veces que era también un poco grosera. Y entonces a veces... una vez así como que me harté y me le paré, como 13 añillos por ahí. Diay teníamos muchos problemillas, no nos llevábamos bien. Nunca he tenido la confianza de decirle: "Mami me siento sola". Nunca he tenido ese tipo de confianza para nada. A veces pasaba yo, a veces pasábamos más que todo yo... porque yo era así... un poco orgullosa, cuando peleábamos a veces pasaba tiempo sin hablarle. A veces no quería hablarle en un año, yo me lo proponía, "no le voy a hablar en un año"... decía yo.

Reaparece la edad en diminutivo (antes "chiquilla") y una vez más, a propósito de cuestiones no consideradas necesariamente positivas: ser histérica, desobedientes, grosera, orgullosa. Este último rasgo se ve directamente relacionado con el silencio, una no interacción con su madre, al tiempo de que hay algo que se explicita como indecible: "me siento sola". Hay también silencios por parte de J. hacia su madre acerca de su orientación sexual, así como de los diversos y reiterados "traumillas", "cosillas" o "malos momentillos". En cuanto a la relación con su madre, J. la describe como un vaivén entre violencia e indiferencia.

Respecto a cierta "historia", la madre de J. migra a Costa Rica junto con ella cuando tiene tres años de edad y establece una relación con una nueva pareja con quien tendrá tres hijos más. Tanto la madre de J. como su padrastro trabajan jornadas completas, por lo que J. y demás hijos quedaban solos o bajo condiciones de cuido precario. En algunas ocasiones, los her- 
manos menores quedaban bajo el cuido de la misma J. La madre de J. fue entrevistada en la investigación mencionada al inicio (Hidalgo, 2011), en la cual describe la relación con su madre y la de esta con la suya (bisabuela de J.) como de una agresividad brutal, con episodios de violencia psicológica y física severa. Hay cuatro generaciones implicadas en vínculos de agresión madre-hija, además todas ellas madres solteras, a excepción de J. ¿Es alejarse de los "maecillos", de "el hombre" una forma de salir de este legado materno? De cierta forma. No obstante, cabe destacar que al momento de las entrevistas J. trabajaba en labores de cuido de niños. De esta manera, podría estar cumpliendo un rol de madre como sib, incluso para sus hermanos menores.

\section{Bloqueo}

Se relaciona con decir "no recordar", pero sí hacerlo, y viceversa. Más que en la forma, representan silencios en la estructura narrativa, algunos cubiertos con mucho ruido. Vale recordar que el silencio es fundamental dentro de la teoría de género respecto a lo femenino, pero especialmente a lo materno (Hirsch, 1989), lo cual implica la hijedad. Empezando con decir no recordar y sí hacerlo, además de seguir en las relaciones madre-hija, se presenta a continuación el duodécimo fragmento:

M.: Ah... es que mi abuela no quiere a mi mamá, entonces por eso no se llevan bien.

EE: ¿Y por qué será que no se llevan bien?

M: No sé, no le he preguntado, y si le menciono algo se enoja.

EE: ¿Quién se enoja, su abuela?

M: Sí.

EE: ¿Y su mamá qué dice?

M: Que no sabe tampoco, pero que siempre ha sido así, desde que la conoció era así, desde que eran novios.

EE: ¿Se acuerda de algo de esa época, qué le han contado?

M: Dice mi mamá que mi papá tenía muchas novias, y que tenía una que mi abuela sí quería mucho, y que como mi papá no andaba ya más con ella sino con mi mamá, entonces que por eso no la quería.

Dice que ni ella ni su madre saben, seguidamente dice el porqué, mismo que, de manera curiosa, sabe gracias a su madre. Se vislumbra que M. desea conocer sobre la enemistad entre su abuela y madre, no obstante, al interrogar a la primera se enoja y la segunda responde con una denegación: "no sé, pero sí sé". Hay un elemento crucial: la conexión del porqué su madre y abuela paterna no se llevan bien surge del tema de las "muchas novias". En la primera entrevista con M., mencionó que cuando su familia migró de Nicara-

\footnotetext{
6 El término maternidad como sí es propuesto por Hidalgo (2011) para referirse a las madres que dejan a sus hijos e hijas en el país de origen y que al insertarse en labores domésticas asumen como propio el cuido de hijas e hijos de empleadores, dándose una compleja dinámica afectiva respecto a hijos/ hijas e hijos/hijas como sí.
} 
gua a Costa Rica fue ella quien supo de la infidelidad de su padre (motivo de separación de sus padres), y quien, de forma posterior, lo dijo a su madre, lo cual no deja de darle cierta sensación culposa. En este fragmento es posible considerar que hay un acercamiento a los motivos del bloqueo, es decir, se evita lo que disgusta, angustia y duele, estrategia que parecen ejercer madre e hija. Su abuela se disgusta ante lo que evita. Los secretos se hacen silencios, los silencios se hacen olvidos que se recuerdan, pero enojosamente. En esa línea se encuentra el décimo tercer fragmento, ahora de la participante B.:

EE: ¿Y en los recreos que hacías?

B.: Diay no, tal vez lo de los recreos es que la gente los... la mente lo ha suprimido porque no me acuerdo... tal vez [risas de B.]... No, no, no, solo me acuerdo de ciertas imágenes de los recreos, que yo me quedaba dentro del aula, o que yo salía afuera a medio conversar, pero no que haya jugado con alguno de ellos. No... solo me acuerdo que me gustaba un chiquito, que yo le escribía cartas y, tal vez, cuando él estaba afuera yo aprovechaba para poner la carta en el pupitre, y qué sé yo, un confite, eso es lo que me acuerdo nada más [risas de B.]. Sí, y entonces así fue la escuela. Cuarto apenas lo pasé, ya después quinto, ya no me acuerdo de quinto y ya después sexto, sexto fue terrible, casi no paso el año...

La apertura a recordar se da luego de un par de pausas y de un "tal vez" y un "no, no, no". Además, en las frases destacadas se evidencia la oscilación entre el recuerdo y el olvido, lo cual evidencia una clara tensión entre recordar, callar, olvidar, decir, titubear, memoria y palabra. B. emigra con su familia a Costa Rica, siendo una niña en edad escolar, y su experiencia en la escuela y el colegio estuvo marcada por formas de discriminación de carácter xenofóbico muy intensas. "Nica hedionda, nica hedionda, cállese", le dijo una vez una compañera, que luego se hizo su amiga. Durante la escuela, recién llegada de Nicaragua, su experiencia estuvo marcada por el rechazo, la humillación, la soledad y la angustia de sentirse diferente y no ser reconocida ni valorada por los otros. En los recreos pasaba generalmente sola, porque no tenía amigas ni amigos. Estas experiencias de rechazo, discriminación y violencia xenofóbica parece que provocan un deseo de olvidar para protegerse del dolor, la frustración y el enojo que provocaban. Frente al olvido surge solo un recuerdo reparador en torno a su deseo oculto por un niño. En el siguiente -décimo cuarto- fragmento encontramos de nuevo en B. una tensión entre recuerdo y olvido como momentos inseparables, se recuerda olvidando y se olvida recordando:

EE: ¿Vos te acordás cuando llegaste aquí [Costa Rica]?

B.: Sí, como si fuera ayer...

EE: ¿Qué te acordás de ese momento en que llegaste aquí?

B.: Diay... bueno, cuando vinimos, diay, me acuerdo como que fue bonito, no lo vi así como irse a otro lugar, simplemente lo vi como un viaje. Yo venía muy ilusionada, traía una imagen del país o del lugar donde íbamos a estar diferente, una ciudad bonita... y este... Y no, aun cuando vinimos aquí, yo no vi feo, digamos la casa de mi tía o el lugar donde íbamos a vivir lo vi como muy bonito. 


\section{EE: ¿Quiénes venían? ¿Vos con tus hermanos?}

B.: Veníamos... sí, mis papás... él [su padre] se fue varios días antes, para arreglar lo que fue lo del salvoconducto, vinimos con salvoconducto. Y, este... ajá, yo me acuerdo, yo fui con él a hacer la última vuelta del salvoconducto. Me acuerdo cuando íbamos en el bus... o no me acuerdo si era en el bus o la bici, que a él le gusta mucho andar en bici, entonces no me acuerdo si era la bici o en qué me llevaba él. Entonces fuimos a hacer las vueltas y llegamos eh... creo que fue el día antes de venirnos, creo que salimos a las tres de la mañana de allá, este... Me acuerdo cuando comenzamos ya, llegó mi hermana, a despedirnos, con el entonces pareja de ella, mi hermana mayor, que fue la última o penúltima... antepenúltima vez que la vimos, porque desde entonces nada más la he visto dos veces.

En esta ocasión también se da lugar a pausas en el ritmo, algunas representadas por puntos suspensivos, así como también lo oscilatorio. Hay cierta nebulosidad entre lo que se dice recordar y lo que se recuerda... y no se dice. Curiosamente inicia como un recuerdo de ilusión y esperanza, que termina recubriendo que fue la última o penúltima vez en que vio a su hermana mayor. Los recuerdos del momento de la migración se ven acompañados de una clara ambivalencia, entre la ilusión y alegría del viaje, los procesos de pérdida y duelo que marcaron su salida de Nicaragua y su llegada a Costa Rica. El décimo quinto fragmento es ilustrativo en cuanto a cierta necesidad de ornamentar con olvido lo disgustante en una relación de pareja:

EE: Era amigo en tu casa ¿y después cuánto duraron? ¿Fue largo, cortito?

K.: No me acuerdo, no sé, no me acuerdo.

EE: Pero fue digamos como 2 o 3 meses, o un año.

K.: No sé, creo que poco...

EE: Poco...

K.: No sé, pero es que fue malo, me hizo una trampa... él es tranquilo, pero como que desconfió no sé, me hizo esa jugada, se hizo pasar por otra persona a ver si yo respondía.

EE: $Y$ no le respondiste.

K.: No. Pero no sé, yo lo veía como... primero eso y después, no, no, ya no me acuerdo.

EE: ¿Pero te dio cólera?

K: Ah sí, cuando me di cuenta que era él. Porque ya cuando me di cuenta que era él sí me enojé.

Ese "después" queda en suspenso, cubierto por un "no, no, ya no me acuerdo". Tomando las palabras de K., se vislumbra que el olvidar o no saber se da como posible evitación de algo malo que le hace su pareja, teniendo ella 19 años, y que le produce dolor y enojo. Es importante aclarar que en el momento de la entrevista K. tiene 24 años y está viviendo una experiencia reciente de separación de una nueva relación de pareja caracterizada por la violencia de género. Ella se acaba de separar y de poner la denuncia por 
agresión, por lo que él tiene prohibición de acercarse. Tanto en la escena anterior como en la relación actual se repite una experiencia de celos con sus parejas, que se caracterizan por formas de control y violencia hacia ella como mujer. En este caso, el bloqueo se acerca a la función del diminutivo visto en los fragmentos de J. El décimo sexto fragmento es también ejemplificador a este respecto:

K.: Es que la memoria se me fue, olvidó, se me puso horrible ya ni me acuerdo. EE: ¿Pero sí fue el año pasado?

K.: Sí, fue el año pasado. Yo el año pasado estuve allá. Fui al principio y después me salí.

EE: ¿Se te juntó todo entonces? La relación violenta, dejar los cursos de la $U$, el examen de matemáticas, la sensación que no era la carrera que querías.

Quien entrevista hace una puntualización, particularmente acorde con lo expuesto en lo comentado en el fragmento anterior, el que se juntara todo - dificultades todas ellas vale subrayar- propicia que la memoria se le vaya, que se le ponga horrible, que olvide. En medio de esta relación de pareja caracterizada por la violencia de género, K. termina dejando las materias de la universidad y también una experiencia laboral. De manera que el olvido aparece como posible defensa ante la parálisis que vive en su vida en este momento.

Retomando la virtualidad de la narrativa para efectos temporales, la mayoría de las entrevistadas dijo no tener interés actual en tener pareja, ni siquiera a futuro, ya que varias de las anteriores fueron relaciones violentas. Por ejemplo, hablan de que no descartan ser madres, pero no de la relación de pareja que, para ellas, implica el ser madres ${ }^{7}$. Hay una conexión entre el no querer/poder recordar relaciones de pareja de su pasado como forma de no pensar en posibles relaciones en un futuro: olvido para no planear. El borramiento se vuelve atemporal o, más bien, recorre las diferentes temporalidades simples (pasado, presente, futuro) de nuestra lengua. Sin embargo, lo visto en la dimensión de la repetición ostenta vigencia en tanto -incluso a nivel narrativo-, se repite como una manera de recordar. Dicho de otra forma, la palabra funciona también como un recordatorio que puede cristalizarse en y a futuro, o hacer del presente un lugar más habitable. Precisamente el bloqueo como protección se dilucida en el décimo séptimo fragmento:

Jn.: No, vivía con ellos dos, la hermana mayor de mi papá que es minusválida, con C., con mis hermanos, y somos cuatro, dos mujeres y dos hombres. Hay un lapso, a los 6 años entré yo a la escuela, no... a los 5, a los 6 años o 5 años, bueno a los 5-6 años para atrás no recuerdo nada. Es como raro, porque sucedieron cosas muy feas que a mí mi abuela me las dice y yo no me acuerdo.

7 Una beta distinta a lo que menciona Herrera en cuanto "las hermanas-hijas-madres entrevistadas insistieron todas en que su maternidad significó "haber fallado" a sus padres y una gran decepción, pues veían ahí el fracaso de su proyecto vital" (2013, p. 148). Para nuestras entrevistadas, parece que el fracaso se juega más en una mala escogencia de pareja que en el ser madres. 
Tal vez, bueno [pasaje borrado a petición de la entrevistada] cuando yo tenía 4 años, y yo miré y no me acuerdo, lo sueño.

EE: ¿Lo qué?

Jn.: Lo sueño. Bueno al hombre que [fragmento borrado a petición de la entrevistada] -que ya se murió gracias a Dios, se lo puedo describir todo, pero a mi recordarme de algo, es hasta que lo sueñe que lo recuerdo. Pero eso está como borrado de mi memoria. Luego otras cosas que pasaron con [fragmento borrado a petición de la entrevistada], tampoco me acuerdo, mi abuela me dice y mi mamá también, y mi hermano que estaba conmigo y yo no me acuerdo ... Ya en sexto grado sí me acuerdo.

EE: ¿No recuerda nada, ningún juguete que tenía, qué jugaba, ropa que tenía, lugares a los que iba... nada?

Jn.: Nada, de primero para abajo nada. Tengo fotos [risas de Jn.], pero recuerdos nada. Recuerdo cuando entré a la escuela, de ahí para atrás nada, y aún hay cosas de la escuela que no recuerdo, que mi abuela me ha dicho y nada. $Y$ eso que tengo muy buena memoria. Puedo decirte fechas, todos los nombres de mis compañeros con nombres y apellidos, de sexto grado que se graduaron conmigo, sus direcciones. Cuando voy a Nicaragua voy a visitar a mis amigos.

La abuela -a quien Jn. ve como madre- le cuenta estas "cosas muy feas", pero ¿con qué propósito? ¿Tiene posibilidad como hija de no escuchar estas cosas que la instigan a recordar algo que bloqueó? El recurso no es el de ensordecer sino de arrinconar dichos recuerdos, los cuales se manifiestan a través de los sueños. Este bloqueo es de tal potencia que arrastra hacia el olvido cosas que no tienen que ver con estos hechos, tan siquiera las palabras de sus familiares ni materialidades del recuerdo (fotos por ejemplo) ayudan. Además afirma tener muy buena memoria. De hecho, y en congruencia con lo expuesto en las consideraciones teóricas sobre la memoria, parece olvidar muy bien, al recubrir con recuerdos "triviales" como fechas, nombres, apellidos y direcciones de ex-compañeros. Es ese ruido que cubre un silencio, al cual se hizo alusión anteriormente. Vale detenerse en el entrecomillado de la palabra "triviales" ya que, pese a asomarse como datos superficiales, sirven como recurso mnémico, ejemplificando la idea de que no todo lo "accidental" es falla.

\section{Consideraciones finales}

La subjetividad no es una cuestión individual. El lenguaje es una de las más ilustrativas expresiones de esto. Usualmente se analiza el contenido, lo enunciativo del discurso y no tan frecuentemente su enunciación. En la dialéctica del qué, y el cómo se dice lo dicho, se encuentran también trazos de comprensión de experiencias de vida: lo biográfico se inscribe en la palabra, en su musicalidad.

Las narrativas de las participantes, en conjunto, brindan una perspectiva fresca sobre el vivir como mujer la migración de mi madre -y en ocasiones su propia migración-, en tanto el relato de lo acontecido alrededor o en medio de la migración es dicho de cierto modo, o más bien en el modo mismo: 
lo inefable puede ser dicho de soslayo, ciertos temas (tanto recuerdos como olvidos) se tocan, rosan, bordean o atraviesan de manera titilante. No se vuelve azaroso que, por ejemplo, se afirme desconocer algo que quiere ser olvidado o se recubra de convencimiento cuestiones inciertas, nebulosas, o que se empleen diminutivos sobre temas a los que se les quiere reducir la importancia o la violencia de lo indecible. Este carácter performativo de lo dicho también se encontró respecto a la repetición, la cual aparece mayoritariamente a propósito de escenas de violencia, mismas que tienden a repetirse en relaciones parento-filiales y/o de pareja.

Los vínculos entre la forma narrativa y lo biográfico son sutiles, por lo que se recomienda tomar en cuenta esta dimensión del discurso. Quizá es un asunto muy evidente, casi de sentido común. No obstante, las maneras en que se presenta a la hora de, por ejemplo, una entrevista en profundidad, son muestra de que, para investigar ciertas temáticas -especialmente aquellas sensibles para el sujeto investigado- se requiere no solo una preparación técnico-metodológica, sino cierta perspicacia de quien entrevista, rigurosidad de quien transcribe en el pasaje de lo fonético a lo escrito, y un oído/ojo sensible a la palabra en su literalidad.

Los así llamados "accidentes" narrativos, se presentan también como recursos valiosos para vivir sin quedar estancadas en situaciones, lugares o roles nocivos; situaciones de agresión, rechazo, abuso, maltrato, hostilidad, sobrecarga, entre otras, que están claramente vinculadas a acontecimientos relacionados con la migración y/o al ser mujer. No obstante, pese a vislumbrarse algunas continuidades, hay también quiebres o resoluciones a dichas experiencias y condiciones de vida a las que como jóvenes hicieron y siguen haciendo frente. El acercarse a otras personas que comparten vivencias similares, hablar de ello e incluso hacerlo en una entrevista en profundidad o grupo focal, son propuestos como espacios valiosos para la criticidad, caer en cuenta, reparar y reconstruir memorias en las que cohabitan momentos desgarradores y/o inspiradores, todos ellos significativos.

Lo inolvidable es también importante, ya que forma parte de la construcción histórico-vital (no toda repetición como recordatorio es negativa), por lo que ciertos relieves -aun siendo toscos- de nuestra memoria parecen constituir baluartes biográficos que inciden en distintos niveles del tejido social. Por tanto, "pulir la memoria, disciplinarla, tendrá que ver también con los intentos de "suavizar" las situaciones de ruptura, en un afán de propiciar así una ilusa "reconciliación" cuando hayan ocurrido graves fisuras sociales" (Dobles, 2009, p. 136). En América Latina algunos de estos "pulidos" o políticas de la memoria han llevado a la indiferencia colectiva, a elecciones o reelecciones inauditas, pero quizá mayormente a la impunidad. Se enlaza, entonces, esa disciplina mnémica, como acto biográfico, con la construcción de narrativas culturales como proceso socio-histórico, mismas que -aún establecidas en 143 lo social o desde lo institucional- se fraguan en modos discursivos en los 
que se entremezcla no solo el qué y el cómo puede ser dicho algo (Foucault, 2008), sino el qué y el cómo se lo ha de recordar, incluso a nivel individual. De manera particular, entre historia vivida e historia narrada, se da una "transición que ocurre por intermediación de los procesos selectivos, de silenciamiento voluntario, de olvido voluntario o pasivo, de una manera personal de organizar la comunicación y jerarquización de los hechos y experiencias por relatar" (Aceves, citado por Dobles, 2009, p. 136), transición que bien puede darse como una oscilación.

Estos procesos selectivos de silenciamiento, olvido y recuerdo forzado llevan a preguntarse: ¿cuántos "accidentes" habrá en nuestras narrativas históricas que constituyen las interconectadas esferas de relacionamiento humano? Los "accidentes" representan una vía por la cual interrogar la tan conveniente oficialidad de dichas narrativas; la reconstrucción histórica que signifique nuevos lazos como naciones, etnias, grupos, familias, sujetos; la razón para hacerlo.

\section{Referencias}

Alberca, Manuel. (2007). El pacto ambiguo. De la novela autobiográfica a la autoficción. España: Biblioteca Nueva.

Benjamin, Walter. (1940). La dialéctica en suspenso. Fragmentos sobre la historia. Santiago: Arcis y Lom.

Berrecil, María; González, Abel y Ampudia, Amada. (s. f.). Caracterización de hijos e hijas de jornaleros agrícolas migrantes del Estado de Oaxaca. México: Organización Internacional del Trabajo, Universidad Nacional Autónoma de México y Universidad Autónoma Chapingo.

Biglia, Barbara y Bonet-Martí, Jordi. (2009). Narrative Construction as a Psychosocial Research Method: Sharing Writing Practices. Forum Qualitative Sozialforschung / Forum: Qualitative Social Research, 10(1). Recuperado de http://nbnresolving. de/urn:nbn:de:0114-fqs090183

Carcedo, Ana; Chaves Groh, María y Lexartza, Larraitz. (2011). Cadenas globales de cuidados: El papel de las migrantes nicaragüenses en la provisión de cuidados en Costa Rica. Madrid: ONU Mujeres y Agencia Española de Cooperación Internacional y para el Desarrollo.

Carcedo, Ana; Chaves Groh, María y Lexartza, Larraitz. (2012). Mujeres centroamericanas en las migraciones. Una mirada alternativa frente un discurso homogeneizante sobre las migraciones. Centro Feminista de Información y Acción y Servicios de Consejería de Proyectos .

Carrillo, María Cristina. (2005). "El espejo distante. Construcciones de la migración en los jóvenes hijos e hijas de emigrantes ecuatorianos". En La migración ecuatoriana. Transnacionalismo, redes e identidades 
(pp. 361-373). Quito: Facultad Latinoamericana de Ciencias Sociales [FLACSO].

Cornejo, Marcela. (2008). Political exile and the construction of identity: A life stories approach. Journal of Community \& Applied Social Psychology, 18(4), 333-348.

Cornejo, Marcela; Mendoza, Francisca y Rojas, Rodrigo. (2008). La investigación con relatos de vida: pistas y opciones del diseño metodológico. Psykhé, 17(1), 29-39.

Dobles, Ignacio. (2009). Memorias del dolor. Consideraciones acerca de las Comisiones de la Verdad en América Latina. Costa Rica: Editorial Arlekín.

Fondo de las Naciones Unidas para la Infancia [UNICEF]. (2012). Sus derechos trascienden fronteras. Diagnóstico nacional sobre protección de derechos de niños, niñas y adolescentes en el contexto de la migración. Bolivia: UNICEF.

Foucault, Michel. (2008). El orden del discurso. Barcelona: Fábula Tusquets Editores.

Freud, Sigmund. (1901 [1986]). Psicopatología de la vida cotidiana. En Obras completas, Tomo VI. Buenos Aires: Amorrortu Editores.

Galeano, Eduardo. (2009). La uva y el vino. En El libro de los abrazos. España: Siglo XXI Editores.

Habermas, Tilmann. (2011). Autobiographical Reasoning: Arguing and Narrating from a Biographical Perspective. En Tilmann Habermas (Ed.) The development of Autobiographical Reasoning in Adolescence and Beyond. New Directions for Child and Adolescent Development, 131 (pp. 1-18). USA: Jossey-Bass.

Herrera, Gioconda. (2013). "Lejos de tus pupilas" Familias transnacionales, cuidados y desigualdad social en Ecuador. Quito: FLACSO.

Hidalgo, Roxana. (2011). Feminidad, migración y trabajo doméstico en Costa Rica: entre la servidumbre y la resistencia. Buenos Aires/San José: Consejo Latinoamericano de Ciencias Sociales/Universidad de Costa Rica.

Hirsch, Marianne. (1989). The Mother/Daughter Plot: Narrative, Psychoanalysis, Feminism. United States of America: Indiana University Press.

Jampaklay, Aree y Vapattanawong, Patama. (2013). The Subjective WellBeing of Children in Transnational and Non-Migrant Households: Evidence from Thailand. Asian and Pacific Migration Journal, 22(3), 377-400.

López, Gustavo. (2007). Niños, socialización y migración a Estados Unidos. En El país transnacional: migración mexicana y cambio social a través de la frontera. México: Instituto de Investigaciones Sociales-Universidad 
Micolta, Amparo. (2011a). Las relaciones en el cuidado de hijos e hijas de migrantes en el país de salida. El caso de Colombia. Presentado en el IV Congreso de la Red Internacional de Migración y Desarrollo. "Crisis global y estrategias migratorias: hacia la redefinición de las políticas de movilidad". Realizado el 18, 19 y 20 de mayo de 2011. Quito: FLACSO.

Micolta, Amparo. (2011b). La autoridad en el cuidado de hijos e hijas de madres y padres migrantes. Revista Latinoamericana de Estudios de Familia, 3, 9-24.

Muro, Alexandra. (2011). Textos sociolingüísticos. Venezuela: Universidad de los Andes.

Pavez-Soto, Iskra. (2010). La participación infantil en los procesos migratorios. Las niñas y los niños de familias peruanas en Barcelona. Papers, 95(2), 441-455.

Puyana, Yolanda y Rojas, Alejandra. (2011). Afectos y emociones entre padres, madres e hijos en el vivir transnacional. Trabajo Social, 13, 95-110

Tizziani, Ania. (2013). De madres a hijas: trabajo, familia y reproducción social. Revista de Estudios Sociales, 45, 248-251. Recuperado de http:// dx.doi.org/10.7440/res45.2013.21

Zapata, Adriana. (julio-diciembre, 2009). Familia transnacional y remesas: padres y madres migrantes. Revista Latinoamericana de Ciencias Sociales, Niñez y Juventud, 7(2), 1749-1769. 